\title{
Malignant Mixed Neoplasm
}

National Cancer Institute

\section{Source}

National Cancer Institute. Malignant Mixed Neoplasm. NCI Thesaurus. Code C3729.

A malignant neoplasm composed of a carcinomatous epithelial component and a sarcomatous mesenchymal component. Representative examples include malignant mixed mesodermal (Mullerian) tumor of the female reproductive system and carcinosarcoma of the salivary gland and the lung. 